\title{
Postpartum Depression and Birth Experience in Russia
}

\author{
Vera A. Yakupova ${ }^{a^{*}}$, Anna Suarez ${ }^{\mathrm{b}}$ \\ ${ }^{a}$ Lomonosov Moscow State University, Moscow, Russia \\ ${ }^{b}$ University of Helsinki, Helsinki, Finland \\ ${ }^{\star}$ Corresponding author: vera.a.romanova@gmail.com
}

Background. In European countries, postpartum depression (PPD) occurs in $13-19 \%$ of women. The statistics indicate that postpartum depressive disorders affect up to 300,000 women in Russia annually. There is still an extremely acute lack of psychological comfort provided to women during labor in Russia.

Objective. To our knowledge, ours is the first study that examines the association between childbirth experience and the risk of PPD in Russia.

Design. We collected data from 190 Russian-speaking mothers, ages 19 to $46,(M=32 \pm 4.3)$ two months after their delivery.

Results. Birth satisfaction and physical well-being two months after delivery were significantly inversely associated with PPD. Birth satisfaction negatively correlated with the perceived severity and unpredictability of labor, and positively correlated with physical well-being two months after delivery. The presence of a partner and a personal midwife or doula at birth was associated with higher birth satisfaction.

Conclusion. Our results emphasize the significance of childbirth satisfaction in the context of PPD and suggest the importance of individual professional support during labor.
Keywords:

postpartum depression (PPD); birth satisfaction; maternal mental health; prevention of postpartum depression; doula support 


\section{Introduction}

Postpartum depression (PPD) occurs in 13-19\% of women globally (O'Hara \& McCabe, 2013), with an estimated overall prevalence of $17 \%$ among healthy mothers without a prior history of depression (Shorey et al., 2018). However, there is a significant heterogeneity of the PPD prevalence across nations, ranging from $3 \%$ in Singapore to $38 \%$ in Chile (Hahn-Holbrook, Cornwell-Hinrichs, \& Anaya, 2018). Therefore, it is important to study PPD within national contexts.

Higher rates of PPD have been observed in nations with significantly higher rates of income inequality, maternal and infant mortality, and women of childbearing age working more than 40 hours a week (Hahn-Holbrook, Cornwell-Hinrichs, \& Anaya, 2018). In Russia, income inequality has increased significantly over the past 30 years (Morgan \& Neef, 2020), and while rates of both maternal and infant mortality have been improving, they are still considerably higher than in the European countries (Danishevski, Balabanova, Parkhurst, \& McKee, 2003). While these factors indicate that we may expect high prevalence of PPD in Russia compared to the global trend, there is a substantial knowledge gap, since no comprehensive studies have addressed the incidence, prevalence, and risk factors for PPD in Russia.

An extensive World Health Organization (WHO) report in 2003 indicated a number of risk factors for PPD (Stewart et al.). The authors showed that a history of psychopathology before and during pregnancy, maternal neuroticism and difficult child temperament, lack of social support, and obstetric difficulties among others, present risk for development of PPD. While obstetric factors were reported to make a small but significant contribution to the development of PPD, the subjective experience of childbirth was not examined in this literature review.

Newer evidence, however, suggests that a traumatic childbirth experience plays a major role in the development of PPD (Bell \& Andersson, 2016; Gosselin, Chabot, Béland, Goulet-Gervais, \& Morin, 2016); our previous studies have corroborated this (Yakupova, 2018). In line with these studies, obstetric violence and medical interventions were associated with increased risk for PPD (Mohammad, Gamble, \& Creedy, 2011; Silveira et al., 2019; Souza, Rattner, \& Gubert, 2017; Xu Ding, Ma, Xin, \& Zhang, 2017). Obstetric violence includes being subjected to mistreatment, disrespect, abuse, negligence, and violation of human rights by health professionals (WHO, 2014), while medical interventions include emergency cesarean section, routine synthetic oxytocin administration, pre-labor rupture of membranes, and episiotomy.

In Russia, modern evidence- and ethics-based obstetric practices are still in their infancy, while the maternity healthcare system largely follows the conservative Soviet approach (Borozdina \& Novkunskaya, 2020). The conservative approach includes a paternalistic style of communication, lack of ethical concern, outdated medical practices, and overall medicalization of birth, with medical personnel focusing primarily on the bureaucratic demands rather than on the patient's needs and psychological comfort (Temkina, 2014).

Studies indicate that maternal psychological well-being after childbirth is associated with a sense of security, the ability to make her own decisions, and continuous 
support during labor (Bohren et al., 2017; Saisto, Salmela, Nurmi, \& Halmesmaki, 2001). However, in Russia, women frequently lack support during labor, since small regional maternity hospitals can still prevent partners from attending the birth, and a doula or private midwife is available only by paid contract, not through the public healthcare sector (Novkunskaya, 2017).

Taken all together, these factors indicate that women may be at higher risk for developing PPD in Russia. However, to our knowledge, no study has investigated this risk or protective factors against it in relation to PPD. Thus, the aim of our study was to examine the association between obstetric factors, childbirth satisfaction, and continuous support during labor with PPD symptoms two months after delivery.

We hypothesized that 1) a higher level of PPD symptoms was associated with a lower level of childbirth satisfaction, poorer physical well-being after delivery, and delivery mode (emergency cesarean vs. elective cesarean vs. vaginal birth); and 2) a higher level childbirth satisfaction was associated with delivery mode (vaginal vs. elective cesarean vs. emergency cesarean birth), better physical well-being after delivery, and mode of birth support (support by a partner, doula or private midwife vs. no support).

\section{Materials and Methods}

\section{Study design}

Data collection took place from June 2018 to February 2019. The women received an invitation to take part in the study through thematic communities and training classes for moms-to-be and new parents. Questionnaires were sent to respondents via e-mail after their written consent to participate was received. The participants were interviewed two months after delivery (the average age of the children was $1.9 \pm 0.22$ months). The inclusion criteria were 1) being at least 18 years old, and 2) giving birth no more than two months ago.

\section{Participants}

One hundred ninety (190) women participated in the study. All participants spoke Russian and lived in big cities (population over 500,000). The characteristics of the sample are presented in the Table 1. More than 96 percent (96.3\%) of the participants gave birth in maternity hospitals and $3.7 \%$ gave birth at home. More than one third $(34.3 \%=65)$ of the participants showed clinically significant depressive symptoms (Table 1).

48.7\% of the participants gave birth in Moscow and the Moscow Region; 14.4\% in other regions of the Russian Federation; 18.2\% in European cities; 9.6\% in Israel; and $9.1 \%$ in former USSR countries.

\section{Procedures}

The Russian version (Yakupova, 2018; Cronbach's $\alpha=0.84$ ) of the Edinburgh Postnatal Depression Scale (EPDS) (Cox, Holden, \& Sagovsky, 1987) was used to esti- 
Table 1

Characteristics of the sample $(N=190)$

\begin{tabular}{|c|c|c|c|c|}
\hline & & $\mathbf{M} / \mathbf{N}$ & $\mathrm{SD} / \%$ & Range \\
\hline Age at testing (years) & & 32 & 4.3 & $19-46$ \\
\hline \multirow[t]{2}{*}{ Education } & Upper secondary/College & 16 & $8.4 \%$ & \\
\hline & Tertiary/University & 174 & $91.6 \%$ & \\
\hline \multirow[t]{3}{*}{ Family status } & Married & 158 & $83 \%$ & \\
\hline & Cohabiting with a partner & 27 & $14.5 \%$ & \\
\hline & Single & 5 & $2.5 \%$ & \\
\hline $\begin{array}{l}\text { Time passed after the } \\
\text { childbirth (months) }\end{array}$ & & 1.9 & 0.22 & $1.7-2.1$ \\
\hline Gestational age & & 39.4 & 1.6 & $37-42$ \\
\hline \multirow[t]{2}{*}{ Parity } & Primiparous & 82 & $43 \%$ & \\
\hline & Multiparous & 108 & $57 \%$ & \\
\hline \multirow[t]{3}{*}{ Delivery mode } & Vaginal & 139 & $73 \%$ & \\
\hline & Emergency cesarean & 23 & $12 \%$ & \\
\hline & Elective cesarean & 28 & $15 \%$ & \\
\hline \multirow[t]{4}{*}{ Mode of birth support } & No support & 69 & $36.1 \%$ & \\
\hline & Partner & 75 & $39.3 \%$ & \\
\hline & Doula/Private midwife & 15 & $8.2 \%$ & \\
\hline & Partner + Doula/Private midwife & 31 & $16.4 \%$ & \\
\hline EPDS score & & 7.9 & 2.3 & $0-21$ \\
\hline $\begin{array}{l}\text { EPDS scores } \geq 10 \text { (clini- } \\
\text { cally significant PPD } \\
\text { symptoms, yes) }\end{array}$ & & 65 & $34.3 \%$ & \\
\hline $\begin{array}{l}\text { Physical health in } 2 \\
\text { months after delivery }\end{array}$ & & 4.2 & 0.8 & $2-5$ \\
\hline $\begin{array}{l}\text { Perceived severity of } \\
\text { labor }\end{array}$ & & 2.5 & 1.1 & $1-5$ \\
\hline Expectations about labor & & 2.9 & 1.2 & $1-5$ \\
\hline BSS-RI score & & 7.3 & 2.2 & $0-10$ \\
\hline \multirow[t]{4}{*}{ Type of the birth support } & No support & 7 & 2.6 & $0-10$ \\
\hline & Partner & 8 & 1.9 & $0-10$ \\
\hline & Partner + doula/midwife & 9 & 1.7 & $0-10$ \\
\hline & Doula/midwife & 7 & 2.1 & $0-10$ \\
\hline
\end{tabular}

Note. $E P D S=$ Edinburgh Postnatal Depression Scale. BSS-RI = Birth Satisfaction Scale Revised Indicator. 
mate PPD symptoms. It is a 10 -item questionnaire scale rated on a 4 -point Likert scale, ranging from 0 to 3 , which indicates how the mother has felt during the previous week. A score of 10 and higher is considered to indicate symptoms of depression.

The participants were asked to measure the discrepancy between their expectations about labor and real experience ("How closely did your expectations of childbirth match reality?") on a 5-point Likert scale $(1=$ "did not at all" to $5=$ "matched completely"). We also asked the participants to assess the perceived severity of their birth experience ("How hard was the birth experience for you?") on a 5-point Likert scale ( 1 = "easy" to 5 = "extremely hard").

We used the Russian version (Yakupova, 2019; Cronbach's $\alpha=0.70$ ) of the Birth Satisfaction Scale Revised Indicator (BSS-RI), a short 6-item self-report questionnaire, to assess birth satisfaction (the subscales include the level of stress and anxiety, feeling of control, and medical staff support) (Martin, Martin, \& Redshaw, 2017). A 3-point Likert scale was used for each question (range 0-2), with the higher scores representing greater birth satisfaction.

We also asked the participants to assess their health condition at the moment of the screening (two months after delivery) on a 5-point Likert scale ( 1 = "very poor" to 5 = "very good"). Finally, we collected data on the participants' socio-demographic characteristics, such as the number of children, the mode of delivery, gestational age, place and time of delivery, and type of delivery support.

\section{Statistical analysis}

The main variables of the study were: PPD (based on EPDS scores); physical wellbeing after delivery; birth satisfaction (based on BSSR-RI scores); and the subjective severity and unpredictability of labor.

Spearman's correlation coefficient was used to estimate the relationship between PPD, birth satisfaction, physical well-being, and the predictability and subjective severity of labor.

Multiple linear regression analysis examined the factors predicting PPD, where PPD was a dependent variable, and birth satisfaction, physical well-being after delivery, perceived severity of birth experience, and predictability of birth were entered in the model as the independent variables. The data met the assumptions for multiple regression analyses; the residuals were normally distributed after the square root transformation of the dependent variable. Model 1 explored unadjusted associations; Model 2 was adjusted for maternal age, gestational age at birth, and the number of children.

We used the Kruskal-Wallis test to assess the differences in the levels of PPD, physical well-being, and childbirth satisfaction between the groups with different kind of labor support (alone; with partner; with doula or midwife and partner; or with doula or midwife without partner) and mode of delivery. We analyzed the differences in individual support depending on the country of birth by the chi-square test.

All analyses were performed using IBM SPSS Statistics 22. 


\section{Results}

The level of childbirth satisfaction correlated negatively with PPD (rho $=-.28$; $\mathrm{p}<.01)$ (Table 2). Women with higher PPD scores more often perceived their labor as severe $($ rho $=.21 ; \mathrm{p}<.01)$. A serious discrepancy between the reality and expectations of childbirth was negatively associated with satisfaction with childbirth $($ rho $=-.40 ; \mathrm{p}<.01)$.

Table 2

Levels of pre- and postnatal depression birth experience and physical well-being

\begin{tabular}{|c|c|c|c|c|c|}
\hline & EPDS & BSSR-RI & $\begin{array}{c}\text { Physical } \\
\text { well-being } \\
\text { after delivery }\end{array}$ & Predictability & $\begin{array}{l}\text { Severity } \\
\text { of labor }\end{array}$ \\
\hline EPDS & & $-0.278^{\star \star}$ & $-0.398^{\star *}$ & 0.121 & $0.206^{\star *}$ \\
\hline BSSR-RI & & & 0.066 & $-0.399^{\star *}$ & $-0.519^{\star *}$ \\
\hline $\begin{array}{l}\text { Physical well-being } \\
\text { (after delivery) }\end{array}$ & & & & 0.041 & -0.064 \\
\hline Predictability & & & & & $0.419^{* *}$ \\
\hline
\end{tabular}

Note. Rho, ${ }^{* *} p<.01,{ }^{*} p<0.05$; the statistically significant correlations are in bold. EPDS $=$ Edinburgh Postnatal Depression Scale. BSS-RI = Birth Satisfaction Scale Revised Indicator.

No statistically significant relationship was found between the mode of delivery [vaginal (VB), emergency caesarean (ECS), or elective caesarean section (ELCS)], and the level of PPD. Neither did these groups differ in the quality of physical wellbeing after childbirth.

Satisfaction with childbirth was significantly lower in women who had emergency caesarean sections than in those who gave birth vaginally $(\mathrm{H}=8.17 ; \mathrm{p}=.017)$. VB and ELCS women did not significantly differ in their levels of childbirth satisfaction. ECS mothers perceived their delivery as being more difficult than VB and ELCS mothers did $(\mathrm{H}=19.22 ; \mathrm{p}<.001$, and $\mathrm{H}=17.26 ; \mathrm{p}<.001$, respectively). Similarly, the ECS mothers' expectations about the childbirth tended to differ more often from the reality than those of VB mothers $(\mathrm{H}=8.42 ; \mathrm{p}=.015)$ and ELCS mothers $(\mathrm{H}=8.21$, $\mathrm{p}=.003)$.

In our study, $36.1 \%(\mathrm{n}=69)$ of the participants gave birth unaccompanied, while $69.3 \%(\mathrm{n}=121)$ had individual support (Table 1). Women who were accompanied by a midwife and a partner during childbirth showed the highest average level of childbirth satisfaction (Table 1). Significantly higher birth satisfaction scores occurred in the group with doula/midwife and partner support, compared to unaccompanied birth $(\mathrm{H}=-3.32 ; \mathrm{p}=.001)$.

Childbirth satisfaction and well-being after childbirth did not significantly differ based on the country in which the delivery took place. However, there were significant country differences in the support given at the time of delivery, so that in Russia, women gave birth to a child without the support of her partner, a personal midwife or a doula more often than in Europe and Israel $\left(\mathrm{X}^{2}=34.844 ; \mathrm{p}<0.001\right)$. 
Multiple linear regression analysis showed that levels of birth satisfaction, physical well-being after delivery, perceived severity of the birth experience, and the predictability of labor process contributed significantly to the regression model $\mathrm{F}(7,183)=8.80 ; \mathrm{p}<.001$, and accounted for $26 \%$ of the variance in PPD. Significant predictors of PPD were physical well-being after delivery $(B=-2.504 ; \mathrm{p}<.001)$ and birth satisfaction $(\mathrm{B}=-.481 ; \mathrm{p}=.007)$. Controlled for maternal age, gestational age at birth, and the number of children, the model explained 25\% of variance in PPD (Table 3).

Table 3

Multiple linear regression results examining associations with PPD.

\begin{tabular}{lcccc}
\hline & B & SE & $95 \%$ CI & $\mathrm{p}$ \\
\hline Model 1 & & & \\
Birth satisfaction & -.498 & .171 & $-.84:-.16$ & .004 \\
$\begin{array}{l}\text { Physical well-being } \\
\text { in 2 months after }\end{array}$ & -2.542 & .395 & $-3.3:-1.7$ & .000 \\
delivery & & & \\
Model 2 (adjusted for maternal age, gestational age at birth, and parity as covariates) & \\
Birth satisfaction & -.481 & .177 & $-.83:-.13$ & .007 \\
$\begin{array}{l}\text { Physical well-being } \\
\text { in 2 months after }\end{array}$ & -2.504 & .404 & $-3.3:-1.7$ & .000 \\
delivery & & & \\
\hline
\end{tabular}

Note. $B=$ Unstandardized B. SE = Standard Error. $95 \% C I=95 \%$ Confidence Interval. $p=p$-value.

\section{Discussion}

To our knowledge, this is the first study to examine the association between PPD and childbirth experience in Russian women. Our results show that lower birth satisfaction and physical well-being two months after delivery were associated with higher levels of PPD. These findings corroborate previous studies indicating psychologically and physically traumatic childbirth experiences as a serious risk factor for depression after childbirth (Yildiz, Ayers, \& Phillips, 2017). It is further in line with the evidence that acute postpartum pain and persistent pain after delivery are associated with increased risk of PPD (Eisenach et al., 2008).

Our study showed that the mode of delivery (vaginal, emergency caesarean, or elective caesarean section) did not directly correlate with the risk of developing PPD. However, an emergency cesarean section seems to be harder for a woman, as this delivery mode was associated with lower childbirth satisfaction and the realities that fell short of the expectations. Subjectively, such childbirth is perceived as being more difficult.

There are contradictory findings in this regard, with some studies reporting elevated risk of PPD following emergency cesarean section (Yang, Shen, Ping, Wang, 
\& Chien, 2011), while others find no such association (Eckerdal et al., 2018), as is the case in our study. This may be because the important risk factor for postpartum depression is not a mode of delivery per se, but the emotions the woman is experiencing - a fear of an unexpected outcome, a fear for her baby's health, a feeling of guilt, etc. For example, mothers who had a strong antepartum preference for vaginal delivery, and then delivered by cesarean, may be at increased risk for depression in the early postpartum period (Houston et al., 2015). Importantly, this involves the quality of the support the woman gets from relatives and specialists (NoymanVeksler, Herishanu-Gilutz, Kofman, Holchberg, \& Shahar, 2015).

Our study's findings indicate that the level of childbirth satisfaction in Russia does not significantly differ from that in European countries and Israel. Specific to childbirth in Russia were lower rates of partner and doula support during the childbirth (especially in the provinces of Russia). This is the legacy of the Soviet system of obstetrics (Temkina, 2014). The presence of a partner or other family member during labor was only allowed in state hospitals beginning in 2012; nowadays there is a growing trend for an increased number of deliveries with the partner present (Novkunskaya, 2020).

Current Federal legislation in Russia does not establish woman's right to have more than one companion during labor. However, our study shows that childbirth with a doula or individual midwife and a partner's support is associated with higher levels of birth satisfaction and physical well-being after delivery. These results are consistent with the research data on the positive impact of doula assistance on the psychological well-being of women in childbirth (McLeish \& Redshaw, 2019). Thus, a doula may be a mediating specialist who helps the couple to go through the challenging birth experience (Lanning \& Klaman, 2019). The results of our research emphasize the importance of the individual professional support during labor and its possible application for the prevention of PPD in Russia.

\section{Conclusion}

Our study showed that birth satisfaction and physical well-being two months after delivery were inversely correlated with PPD. Perceived severity of labor and worse well-being after delivery were associated with lower birth satisfaction. The presence of a partner and a personal midwife or doula at birth was associated with higher birth satisfaction, which indicates the importance of the individual professional support during labor as a possible avenue for PPD prevention.

\section{Limitations}

We used self-report methods to assess the levels of depression. Clinical interviews would supplement the results and make them more valid. A more detailed questionnaire about the woman's birth experience or a qualitative study would enrich the results about the association between birth satisfaction and perinatal affective disorders. Further research with the larger group with doula or midwife support is needed. 


\section{Ethics Statement}

This study was conducted according to the Declaration of Helsinki. The study was approved by the Ethical Committee of the Russian Psychological Society, approval ID \#18-1102. We affirm that all the participants gave informed consent before taking part in the research.

\section{Author Contributions}

VY and AS conceived of the idea. VY developed the study design and performed the computations. AS verified the analytical methods and standards for results presentation. VY and AS discussed the results and contributed to the final manuscript.

\section{Conflict of Interest}

The authors declare no conflict of interest.

\section{Acknowledgements}

This research was supported by grant 18-313-00051 of Russian Fundamental Research Fund.

\section{References}

Bell, A.F., \& Andersson, E. (2016). The birth experience and women's postnatal depression: a systematic review. Midwifery, 39, 112-123. https://doi.org/10.1016/j.midw.2016.04.014

Bohren, M.A., Hofmeyr, G.J., Sakala, C., Fukuzawa, R.K., \& Cuthbert, A. (2017). Continuous support for women during childbirth. Cochrane Database of Systematic Reviews, 17. https://doi. org/10.1002/14651858.CD003766.pub6

Borozdina, E., \& Novkunskaya, A. (2020). Patient-centered care in Russian maternity hospitals: Introducing a new approach through professionals' agency. Health: An Interdisciplinary Journal for the Social Study of Health, Illness and Medicine. https://doi.org/10.1177/1363459320925871

Cox, J.L., Holden, J.M., \& Sagovsky, R. (1987). Detection of postnatal depression: development of the 10item Edinburgh Postnatal Depression Scale. The British Journal of Psychiatry, 150, 782-786. https:// doi.org/10.1192/bjp.150.6.782

Danishevski, K., Balabanova, D., Parkhurst, J., \& McKee, M. (2003). What do we know about the state of maternal health in Russia? Report on the situation analysis. Retrieved from http://researchonline. lshtm.ac.uk/id/eprint/17934/

Eckerdal, P., Georgakis, M.K., Kollia, N., Wikström, A.K., Högberg, U., \& Skalkidou, A. (2018). Delineating the association between mode of delivery and postpartum depression symptoms: a longitudinal study. Acta Obstetricia et Gynecologica Scandinavica, 97(3), 301-311. https://doi.org/10.1111/ aogs. 13275

Eisenach, J.C., Pan, P.H., Smiley, R., Lavand'homme, P., Landau, R., \& Houle, T.T. (2008). Severity of acute pain after childbirth, but not type of delivery, predicts persistent pain and postpartum depression. Pain, 140(1), 87-94. https://doi.org/10.1016/j.pain.2008.07.011.

Gosselin, P., Chabot, K., Béland, M., Goulet-Gervais, L., \& Morin, A.J. (2016). Fear of childbirth among nulliparous women: Relations with pain during delivery, post-traumatic stress symptoms, and postpartum depressive symptoms. Encephale, 42(2), 191-196. https://doi.org/10.1016/j.encep.2016.01.007

Hahn-Holbrook, J., Cornwell-Hinrichs, T., \& Anaya, I. (2018). Economic and Health Predictors of National Postpartum Depression Prevalence: A Systematic Review, Meta-analysis, and Meta-Re- 
gression of 291 Studies from 56 Countries. Frontiers in Psychiatry, 8, 248. https://doi.org/10.3389/ fpsyt.2017.00248

Houston, K.A., Kaimal, A.J., Nakagawa, S., Gregorich, S.E., Yee, L.M., \& Kuppermann, M. (2015). Mode of delivery and postpartum depression: the role of patient preferences. American Journal of Obstetrics and Gynecology, 212(2), 229.e1-229.e7. https://doi.org/10.1016/j.ajog.2014.09.002.

Lanning, R.K., \& Klaman, S.L. (2019) Evaluation of an Innovative, Hospital-Based Volunteer Doula Program. Health Care Improvement and Evaluation, 48(6), 654-663. https://doi.org/10.1016/j. jogn.2019.08.004

Martin, C.R., Martin, H.C., \& Redshaw, M. (2017). The Birth Satisfaction Scale-Revised Indicator (BSSRI). BMC Pregnancy and Childbirth, 17(1), 277. https://doi.org/10.1186/s12884-017-1459-5

McLeish, J. \& Redshaw, M. (2019). “Being the best person that they can be and the best mum”: a qualitative study of community volunteer doula support for disadvantaged mothers before and after birth in England. BMC Pregnancy and Childbirth, 10, 19-21. https://doi.org/ 10.1186/s12884-018-2170-x

Mohammad, K.I., Gamble, J., \& Creedy, D.K. (2011). Prevalence and factors associated with the development of antenatal and postnatal depression among Jordanian women. Midwifery, 27, 238-245. https://doi.org/10.1016/j.midw.2010.10.008

Morgan, M., \& Neef, T. (2020). What's New About Income Inequality in Europe (1980-2019)? World Inequality Lab. Retrieved from https://wid.world/document/whats-new-about-income-inequalityin-europe-1980-2019/

Novkunskaya, A. (2017). Rody po myagkim metodikam v provincii: vozmojnosti i ogranicheniya [Gentle birth methods in province: opportunities and restrictions]. In Temkina, A. \& Borozdina, E. (Eds.), Menyayuscheesya rodovspomojenie: vzglyad akusherok I sociologov [Changing obstetrics: midwives' and sociologists' perspective] (pp. 31-44). Izdatel'stvo EUSPB [EUSPB Publishing].

Novkunskaya, A. (2020). Some symptoms of neoliberalisation in the institutional arrangement of maternity services in Russia. In Cardano, M., Gabe, J., \& Genova, A. (Eds.) Health and illness in the Neoliberal Era in Europe (pp. 177-193). Emerald Publishing Limited. https://doi.org/10.1108/9781-83909-119-320201010

Noyman-Veksler, G., Herishanu-Gilutz, S., Kofman, O., Holchberg, G., \& Shahar, G. (2015). Postnatal psychopathology and bonding with the infant among first-time mothers undergoing a caesarian section and vaginal delivery: sense of coherence and social support as moderators. Psychology and Health, 30(4), 441-455. https://doi.org/10.1080/08870446.2014.977281

O’Hara, M.W., \& McCabe, J.E. (2013). Postpartum depression: Current status and future directions. Annual Review of Clinical Psychology, 9, 379-407. https://doi.org/10.1146/annurev-clinpsy-050212-185612

Saisto, T., Salmela, A.K., Nurmi, J.E., \& Halmesmaki, E. (2001). Psychosocial predictors of disappointment with delivery and puerperal depression - a longitudinal study. Acta Obstetricia et Gynecologica Scandinavica, 80, 39-45. https://doi.org/10.1034/j.1600-0412.2001.800108.x

Silveira, M.F., Mesenburg, M.A., Bertoldi, A.D., De Mola, C.L., Bassani, D.G., Domingues, M.R., ... Coll, C.V.N. (2019). The association between disrespect and abuse of women during childbirth and postpartum depression: Findings from the 2015 Pelotas birth cohort study. Journal of Affective Disorders, 256, 441-447. https://doi.org/10.1016/j.jad.2019.06.016

Shorey, S., Chee, C.Y.I., Ng, E.D., Chan, Y.H., Tam, W.W.S., \& Chong, Y.S. (2018). Prevalence and incidence of postpartum depression among healthy mothers: A systematic review and meta-analysis. Journal of Psychiatric Research, 104, 235-248. https://doi.org/10.1016/j.jpsychires.2018.08.001

Souza, K.J. de, Rattner, D., \& Gubert, M.B. (2017). Institutional violence and quality of service in obstetrics are associated with postpartum depression. Revista de Saude Publica, 51. https://doi. org/10.1590/S1518-8787.2017051006549

Stewart, D.E., Robertson, E., Phil, M., Dennis, C., Grace, S.L., \& Wallington, T. (2003). Postpartum Depression: Literature review of risk factors and interventions. WHO Publication. Retrieved from https://www.who.int/mental_health/prevention/suicide/lit_review_postpartum_depression.pdf

Temkina, A.A. (2014). Medikalizaciya reprodukcii i rodov: Bor'ba za control' [Medicalization of childbirth: fight for control]. Jurnal issledovaniy social'noy politiki [Journal of Social Policy Research], 12(3): 321-336. Retrieved from https://www.researchgate.net/publication/280546647_ATem- 
kina_2014_Medikalizacia_reprodukcii_i_rodov_borba_za_kontrol_Zurnal_issledovanij_socialnoj_politiki_123_321-336

World Health Organization (2014). The prevention and elimination of disrespect and abuse during facility-based chidlbirth. Genebra: WHO. Retrieved from http://apps.who.int/iris/bitstream/10665/134588/1/WHO_RHR_14.23_eng.pdf?ua=1\&ua=1

Xu, H., Ding, Y., Ma, Y., Xin, X., \& Zhang, D. (2017). Cesarean section and risk of postpartum depression: A meta-analysis. Journal of Psychosomatic Research, 97, 118-126. https://doi.org/10.1016/j. jpsychores.2017.04.016

Yakupova, V. (2018). The Impact of Psychological and Physiological Conditions of Motherhood on Postnatal Depression. Russian Journal of Psychology, 15(1), 8-23. https://doi.org/10.21702/rpj.2018.1.1

Yang, S.N., Shen, L.J., Ping, T., Wang, Y.C., \& Chien, C.W. (2011). The delivery mode and seasonal variation are associated with the development of postpartum depression. Journal of Affective Disorders, 132, 158-164. https://doi.org/10.1016/j.jad.2011.02.009

Yildiz, P.D., Ayers, S., \& Phillips, L. (2017). The prevalence of posttraumatic stress disorder in pregnancy and after birth: A systematic review and meta-analysis. Journal of Affective Disorders, 208, 634-645. https://doi.org/10.1016/j.jad.2016.10.009

Original manuscript received December 24, 2019

Revised manuscript accepted December 22, 2020

First published online March 20, 2021

To cite this article: Yakupova, V.A., Suarez, A. (2021). A Postpartum Depression and Birth Experience in Russia. Psychology in Russia: State of the Art, 14(1), 28-38. DOI: 10.11621/pir.2021.0103 